This document is the Accepted Manuscript version of a Published Work that appeared in final form in ACS Catalysis, copyright $@$ American Chemical Society after peer review and technical editing by the publisher. To access the final edited and published work see https://pubs.acs.org/doi/10.1021/acscatal.7b00355c

\title{
Concerted Chemoselective Hydrogenation of Acrolein on Secondary Phosphine Oxide Decorated Gold Nanoparticles
}

\author{
Neyvis Almora-Barrios, ${ }^{\dagger}$ Israel Cano, ${ }^{\ddagger}$ Piet W. N. M. van Leeuwen, ${ }^{\ddagger \odot}$ and Núria López ${ }^{*} \dagger \oplus$ \\ 'Institute of Chemical Research of Catalonia, ICIQ The Barcelona Institute of Science and Technology, Av. Països Catalans, 16, \\ 43007, Tarragona, Spain \\ ${ }^{\ddagger}$ Laboratoire de Physique et Chimie des Nano-Objets, LPCNO, UMR5215 INSA-UPS-CNRS, Institut National des Sciences \\ Appliquées, 135 Avenue de Rangueil, 31077 Toulouse, France
}

S Supporting Information

\begin{abstract}
Secondary phosphine oxides (SPOs) can be used as ligands to stabilize catalytically active gold nanoparticles (AuNPs). These materials are active and very selective in the chemoselective hydrogenation of acrolein and other $\alpha, \beta$-unsaturated aldehydes, but the origin of the activity remains elusive. Here, by means of density functional theory, we identify a cooperative effect at the AuNP-SPO interface that enables the heterolytic cleavage of the $\mathrm{H}_{2}$ molecule and its kinetically favorable concerted addition to the $\mathrm{C}=\mathrm{O}$ bond (in a transfer hydrogenation-like mode) to form the corresponding allyl alcohol. From the mechanism it is possible to identify the descriptors that explain the activity for a family of SPO-stabilized AuNPs and a set of unsaturated aldehydes. The activity depends on the basicity difference between ligand and reactant and the sites available on the nanoparticle.
\end{abstract}

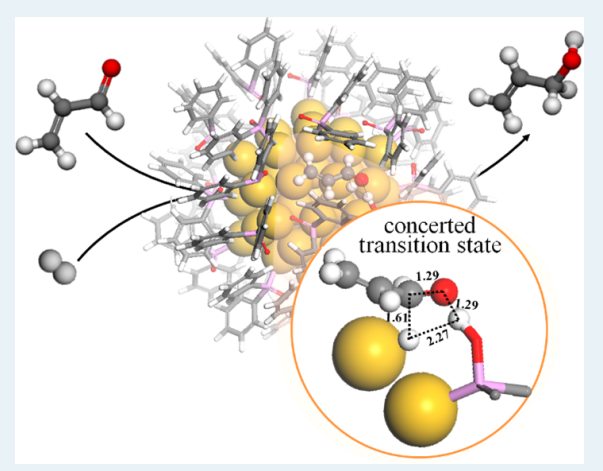

KEYWORDS: gold nanoparticle, concerted, density functional theory, hydrogen activation, chemoselectivity

\section{INTRODUCTION}

The uses of ligand decorated metal nanoparticles (MNPs) are exponentially growing, as they combine the advantages of heterogeneous catalysts with the selectivity provided by homogeneous catalysts. ${ }^{1-12}$ Ligands serve as capping agents, limiting the growth, and thus help to maintain well-dispersed and small size MNPs, even with very well-defined stoichiometries. However, as ligands are chemically bonded to the metals, they can affect the catalytic properties, ${ }^{13-19}$ either by blocking the active metal sites ${ }^{20}$ or altering the properties at the metal/ ligand interface. ${ }^{15,21,22}$ While detailed structural studies of these nanoparticles exist, ${ }^{23}$ the role of the ligands when employed as catalysts is still not fully understood.

The hydrogenation with high chemoselectivity of imines, ketones, and $\alpha, \beta$-unsaturated aldehydes catalyzed by MNPs has been reported. ${ }^{24-26}$ Particularly, the chemoselective hydrogenation of $\alpha, \beta$-unsaturated aldehydes can produce unsaturated alcohols, compounds widely employed in the pharmaceutical and fine chemical industries. ${ }^{27}$ Nevertheless, these products are difficult to obtain because the hydrogenation of $\mathrm{C}=\mathrm{C}$ bonds is thermodynamically preferred (Scheme 1). ${ }^{28,29}$ To drive the selective hydrogenation of $\mathrm{C}=\mathrm{O}$ bonds in the presence of other unsaturations remains a challenge for heterogeneous catalysts. $^{30}$

Gold has attracted growing interest as catalyst due to its intrinsic selectivity in various reactions. ${ }^{31}$ Gold nanoparticles (AuNPs) perform the selective hydrogenation of acrolein to allyl alcohol, but the reported activities were low. ${ }^{32,33}$ The
Scheme 1. Partial Hydrogenation of Acrolein and Reaction Energies with Respect to Acrolein in the Gas-Phase

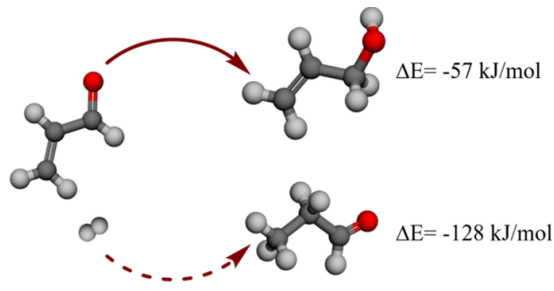

activity of gold can be improved by ligand control. For instance, thiol-modified gold clusters $\left(\mathrm{Au}_{25}(\mathrm{SR})_{18}\right)$ were reported to hydrogenate ketones with high activity and chemoselectivity but for acrolein the selectivity was around $90 \% .{ }^{34}$ Additionally, van Leeuwen et al. described a set of secondary phosphine oxides (SPOs) that can be used as ligands for the synthesis of AuNPs with catalytic properties. The SPO-stabilized AuNPs are highly chemoselective in the hydrogenation of a wide range of substituted aldehydes. ${ }^{35,36}$ Typical conditions for this reaction were $60^{\circ} \mathrm{C}, 40 \mathrm{bar} \mathrm{H}_{2}$, and tetrahydrofuran (THF) as solvent. The characterization showed that the diphenyl phosphine oxide $\left(\mathrm{Ph}_{2} \mathrm{PO}\right)$ ligand covers the surface of the small AuNP (size 1.61 $\pm 0.16 \mathrm{~nm}$, corresponding stoichiometry $\sim 55$-atoms) with a 
metal-ligand ratio around 1.3:1. The reaction mechanism and the factors controlling activity and chemoselectivity have not been identified. We have addressed them by first-principles simulations, identifying that the combination of bulky SPO ligands and a Au nanoparticle core produces a Frustrated Lewis Pair (FLP) ${ }^{24,37}$ that induces the heterolytic cleavage of $\mathrm{H}_{2}$. The resulting $\mathrm{H}_{2}$-ion pair can be selectively transferred only to the $\mathrm{C}=\mathrm{O}$ moiety through a concerted mechanism responsible for the unique chemoselectivity observed.

\section{COMPUTATIONAL DETAILS}

To investigate how activity and chemoselectivity are produced by the SPO-AuNP, we have used dispersion-corrected density functional theory with the the Vienna ab initio simulation package (VASP), ${ }^{38,39}$ which implements the projector augmented wave method (PAW). ${ }^{40}$ The wave function was determined by expansion of the valence electrons with plane waves with kinetic energies up to $450 \mathrm{eV}$, and the $\Gamma$ point was used to sample the $\mathrm{k}$ space. Total energies and electron densities were computed with the Perdew-Burke-Ernzerhof (PBE) functional ${ }^{41}$ complemented by the dispersion D2 term as presented by Grimme ${ }^{42,43}$ with our values for the metals. ${ }^{44}$ First, we have investigated the structure of the SPO coated AuNPs. The pentavalent phosphine oxide interacts with gold and forms the deprotonated phosphinito anion, generating the Au-SPO nanoparticle. The AuNP was considered as an icosahedral structure, containing $55 \mathrm{Au}$ atoms with a diameter of $1.16 \mathrm{~nm}$ and modeled as a hexagonal box with dimensions of $22 \times 22 \times 22 \AA^{3}$. The model of the catalyst (SPO-AuNP) was derived from ref 9 . The structure was modified with the Materials Studio version 6.1 package, and the final simulation system consisted of a $\mathrm{Au}_{55}$ nanoparticle capped with $27 \mathrm{Ph}_{2} \mathrm{PO}$ ligand molecules placed in a box of $30 \times 30 \times 30 \AA^{3}$ size. Upon optimization (Figure 1), the phosphorus atoms sit at an average $\mathrm{Au}-\mathrm{P}$ distance of $2.602 \AA$, and the oxygen atoms at a $\mathrm{Au}-\mathrm{O}$ distance at around $2.9 \AA$. This structure consists of a very densely packed ligand layer on the AuNP surface (correspond-

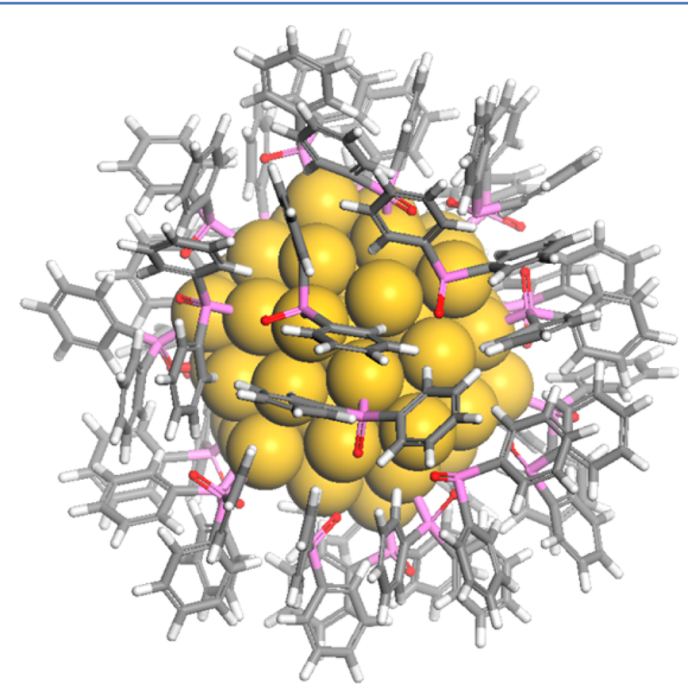

Figure 1. DFT adsorption configuration of $27 \mathrm{Ph}_{2} \mathrm{PO}$ ligands on $\mathrm{Au}_{55}$, corresponding to a metal-ligand ratio of $1.56: 1$ in the range of the experimental results. ${ }^{35}$ Yellow spheres represent $\mathrm{Au}$ atoms, and the stick models represent the adsorbed $\left(\mathrm{Ph}_{2} \mathrm{PO}\right)$. Color codes: $\mathrm{P}$ in pink, $\mathrm{O}$ in red, $\mathrm{C}$ in gray, and $\mathrm{H}$ in white. ing to $1.56: 1$ ratio), in agreement with a metal-ligand ratio in the range 1.32:1-1.84:1 found in the experiments. ${ }^{35}$ The adsorption energy was calculated as $E_{\text {ads }}=E_{\text {mol }+ \text { cat }}-E_{\text {cat }}-$ $E_{\text {mol }}$, where $E_{\text {mol+cat }}$ is the energy of the $A_{55}\left(\mathrm{Ph}_{2} \mathrm{PO}\right)_{27}$ nanoparticle with the adsorbed molecule, $E_{\text {cat }}$ is the energy of the simulation of the $\mathrm{Au}_{55}$ nanoparticle with adsorbed 27 $\mathrm{Ph}_{2} \mathrm{PO}$ species $\left(\mathrm{Au}_{55}\left(\mathrm{Ph}_{2} \mathrm{PO}\right)_{27}\right)$, and $E_{\text {mol }}$ is the energy of the adsorbed molecule in gas phase or in liquid phase. The solvation contribution for the adsorbed molecules in the liquid phase was calculated using the Multigrid Continuum Model (MGCM) methodology. ${ }^{45}$ We considered a variety of different adsorption geometries to identify the energetically most favorable location. Transition states and barriers were obtained using the Climbing Image version of the Nudged Elastic Band (NEB) algorithm. ${ }^{46}$ The determined transition states were verified by having only one imaginary frequency.

\section{RESULTS AND DISCUSSION}

Gold possesses a very limited capacity for hydrogen adsorption. ${ }^{24,26,47} \mathrm{H}_{2}$ homolytic dissociation $\left(\mathrm{H}_{2}+2 * \rightarrow 2 \mathrm{H}^{*}\right)$ on the $\mathrm{Au}(111)$ surface is endothermic by $66.6 \mathrm{~kJ} \mathrm{~mol}^{-1}$, and the barrier is very high, $139.9 \mathrm{~kJ} \mathrm{~mol}^{-1}$. ${ }^{37}$ On the naked $\mathrm{Au}_{55}$ nanoparticle, the energy barrier for dissociation is lower $(75.3$ $\mathrm{kJ} \mathrm{mol}^{-1}$ ) and the reaction is endothermic by $10.1 \mathrm{~kJ} \mathrm{~mol}^{-1}$ (orange line in Figure 2). Thus, even for $\mathrm{Au}_{55}$ the barrier is too high to afford an active catalyst, in agreement with the experimental observations.

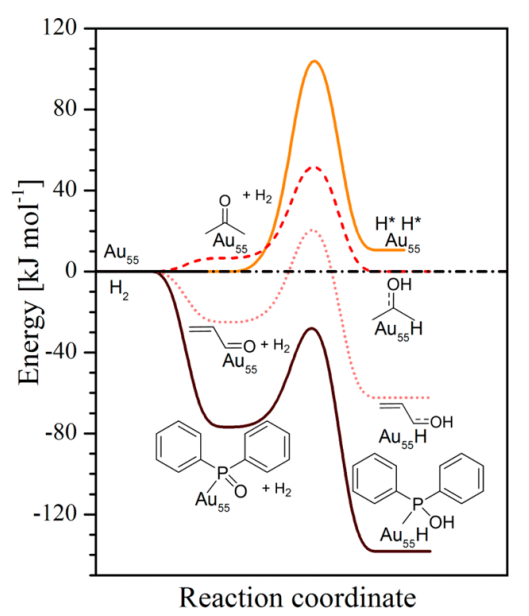

Figure 2. Reaction energy profile for the $\mathrm{H}_{2}$ dissociation on bare $\mathrm{Au}_{55}$ and Lewis bases: acetone, acrolein, and SPO ligands. Color codes: orange: bare $\mathrm{Au}_{55}$, light red short dot: acrolein, red short dash: acetone, and wine SPOs.

This contrasts with the AuNP-SPO model, for which the dissociation of the $\mathrm{H}_{2}$ molecule is exothermic by $61.8 \mathrm{~kJ} \mathrm{~mol}^{-1}$ and shows a barrier of $52.1 \mathrm{~kJ} \mathrm{~mol}^{-1}$ (not ZPVE corrected; see Figure 2 and Supporting Information, Section 1). More importantly, the dissociation is not homolytic, but takes place through a heterolytic path in which the final product is a tight ion pair $\mathrm{H}_{2}+2^{*} \rightarrow \mathrm{H}^{+}+\mathrm{H}^{-}$. The hydride, $\mathrm{H}^{-}$, is adsorbed on the metal site $\left(\mathrm{Au}-\mathrm{H}^{-}\right)$, and the proton, $\mathrm{H}^{+}$, binds to the oxygen atom of the ligand $\left(\mathrm{Ph}_{2} \mathrm{PO}-\mathrm{H}^{+}\right)$. Electrostatic forces stabilize these ions, yielding $\mathrm{H}^{+}-\mathrm{H}^{-}$contacts of $2.11 \AA$ and Bader charges +0.69 and $-0.03 \mathrm{le}^{-} \mathrm{l}$. The AuNP-SPO interface is a Lewis acid-base adduct that fulfills the requirements established by Guo for the formation of Frustrated Lewis 
Pairs. $^{24,37,48}$ Additionally, we have investigated the role of reactants (acrolein or acetone) during the $\mathrm{H}_{2}$ dissociation on bare $\mathrm{Au}_{55}$ (see Figure 2 and Supporting Information, Section 1). In both cases, the $\mathrm{H}_{2}$ molecule dissociates heterolytically, entailing the formation of a hydride on the surface and a proton which bonds to the carbonyl oxygen. This step has an energy barrier similar to that of the same step on AuNP-SPO (Figure 2 ), but the main difference resides in the adsorption energies of acrolein, acetone, and SPO on $\mathrm{Au}_{55}$. The adsorption energy for one SPO ligand is $-84.9 \mathrm{~kJ} \mathrm{~mol}^{-1}$ per $\mathrm{Ph}_{2} \mathrm{PO}$ molecule, but the $27 \mathrm{Ph}_{2} \mathrm{PO}$ ligands interact with the AuNP by $-6.35 \mathrm{~kJ} \mathrm{~mol}^{-1}$ per $\mathrm{Ph}_{2} \mathrm{PO}$ molecule. The adsorption of SPO molecules is favored in comparison to acrolein or acetone because the SPO ligand can be stabilized and, in addition, affects the electronic structure of the AuNP, thus leading to a more effective promotion of the reaction. ${ }^{9}$

When $\mathrm{Au}_{55}$ is decorated with phosphine oxide ligands (AuNP-SPO), the adsorption energy of acrolein $(-23.2 \mathrm{~kJ}$ $\left.\mathrm{mol}^{-1}\right)$ is similar to that of bare $\mathrm{Au}_{55}$, but it is weaker than the adsorption energy of prop-2-en-1-ol $\left(-45.3 \mathrm{~kJ} \mathrm{~mol}^{-1}\right)$. This is due to the hydrogen bond between the $\mathrm{OH}$ of prop-2-en-1-ol and the $\mathrm{O}$ atom of the $\mathrm{Ph}_{2} \mathrm{PO}$ ligand at a distance of $1.399 \AA$. The adsorption energy of propanal is similar to that of prop-2en-1-ol $\left(-40.5 \mathrm{~kJ} \mathrm{~mol}^{-1}\right)$. However, this molecule is at the outer-surface region because the distance between the gold atoms and the subtrate is around $2.5 \AA$. Notwithstanding, when the hydrogen molecule is dissociated by the FLP, the adsorption of acrolein is stronger due to formation of a $\mathrm{H}$ bond between the carbonyl oxygen atom of acrolein and the proton attached to the SPO ligand by $-34.7 \mathrm{~kJ} \mathrm{~mol}^{-1}$ (Figure S3, bottom). We have also studied an alternative model in which the $\mathrm{C}=\mathrm{C}$ bond of acrolein is close to the proton and the hydride, but the adsorption energy does not improve. From these adsorbed structures, we investigated the mechanisms for all possible paths for the competitive hydrogenation of $\mathrm{C}=\mathrm{O}$ and $\mathrm{C}=\mathrm{C}$ bonds (Figure 3 ).

The route to propanal, the thermodynamically preferred product, encompasses two steps. In the most favorable first step, the SPO-H proton is transferred to $\mathrm{C} 3$ of acrolein with a barrier of $59.7 \mathrm{~kJ} \mathrm{~mol}^{-1}$, forming an intermediate lying at $-135.1 \mathrm{~kJ} \mathrm{~mol}^{-1}$. The transfer of the hydride to $\mathrm{C} 2$ is

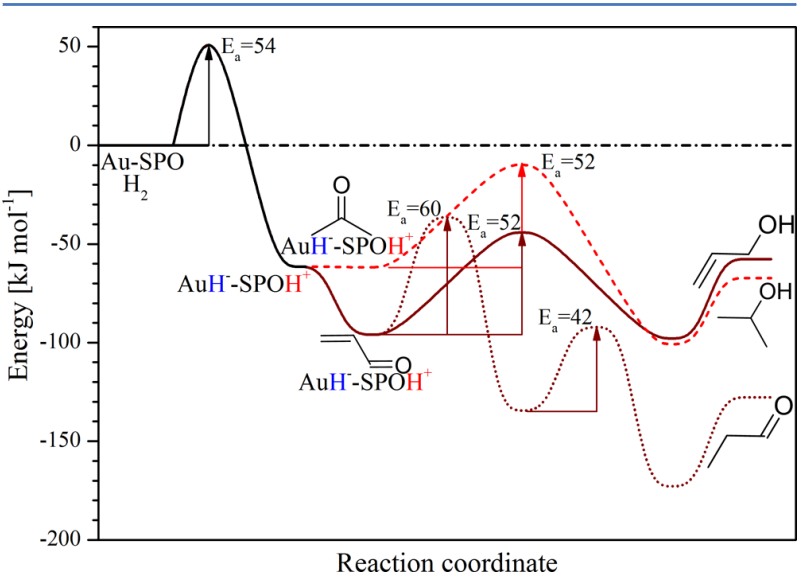

Figure 3. Energy profile for the selective hydrogenation of acrolein and acetone over AuNP-SPO catalyst. Black solid line = heterolytic dissociation of $\mathrm{H}_{2}$, wine dotted line = propanal, wine solid line = prop2-en-1-ol, and red dashed line $=2$-propanol exothermic by $38.6 \mathrm{~kJ} \mathrm{~mol}^{-1}$. Propanal desorption is endothermic by $45.3 \mathrm{~kJ} \mathrm{~mol}^{-1}$.

The competitive formation of desired alcohol takes place through a concerted step, resulting in the addition of the $\mathrm{H}_{2}$ pair to the $\mathrm{C}=\mathrm{O}$ bond. The non-ZPVE corrected barrier is $52.1 \mathrm{~kJ} \mathrm{~mol}^{-1}$ and, thus, $8 \mathrm{~kJ} \mathrm{~mol}^{-1}$ smaller than that of the hydrogenation of the $\mathrm{C}=\mathrm{C}$ bond. The concerted transition state shown in Figure 4 is stabilized by dipolar interactions in a

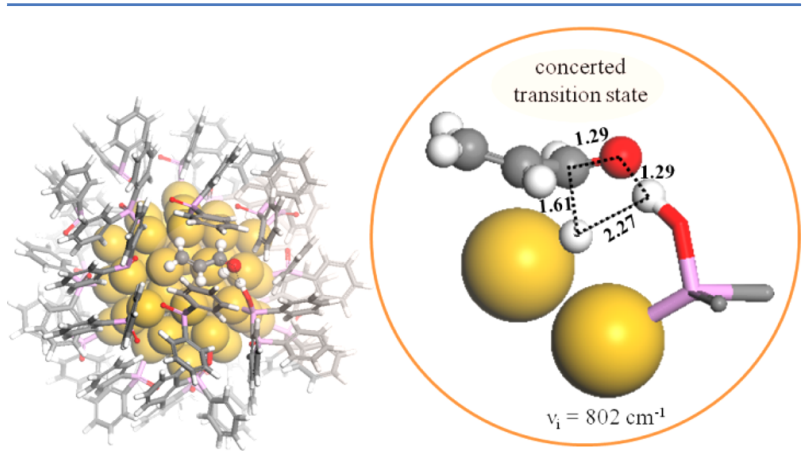

Figure 4. Structure, distances $(\AA)$, and imaginary frequency $\left(\mathrm{cm}^{-1}\right)$ for the transition state corresponding to the concerted mechanism in the hydrogenation of $\mathrm{C}=\mathrm{O}$ of acrolein on AuNP-SPO. The inset highlights the four-membered ring formation and the distances. The same color codes as in Figure 1.

four-membered ring structure formed by the hydride on the gold surface $\left(\mathrm{Au}-\mathrm{H}^{-}\right)$, the proton bound to the oxygen atom of the SPO ligand $\left(\mathrm{Ph}_{2} \mathrm{PO}-\mathrm{H}^{+}\right)$, and the $\mathrm{O}$ and $\mathrm{C}$ atoms belonging to the carbonyl group of acrolein. The TS is nonsynchronous because the $\mathrm{O}-\mathrm{H}$ bond is $70 \%$ formed while the $\mathrm{C}-\mathrm{H}$ bond is $59 \%$ formed, following a geometric criterion for the bond lengths. ${ }^{49}$ This thus resembles a transfer hydrogenation mechanism. ${ }^{50}$ As for other $\mathrm{H}_{2}$ additions assisted by FLP reported in the literature, these reactions are in equilibrium. $^{51}$ Prop-2-en-1-ol desorption is endothermic by $40.5 \mathrm{~kJ} \mathrm{~mol}^{-1}$. The concerted one-step mechanism observed here for the heterogeneous chemoselective hydrogenation of acrolein contrasts with the homogeneous $\mathrm{Rh}-\mathrm{SPO}$ catalyst used in the transfer hydrogenation of ketones in isopropanol, where the seven-membered ring transition state along a concerted outer-sphere pathway is generally preferred. ${ }^{52}$

Furthermore, we have considered the difference in rate between aldehydes and ketones found for the AuNP-SPO catalyst. Acetone interacts only weakly with the AuNP-SPO, even when the hydrogen molecule is dissociated, with the adsorption energy being as low as $-2.9 \mathrm{~kJ} \mathrm{~mol}^{-1}$ (Figure 3 and Table S5). In fact, the different adsorption behaviors between ketones and aldehydes on the AuNP-SPO can be explained by the electrostatic interactions combined with steric effects. The Bader charge reveals that the $\mathrm{C}=\mathrm{O}$ group of the aldehydes is slightly more negatively charged $\left(\sim 0.03 \mathrm{le}^{-} \mid\right)$than the $\mathrm{C}=\mathrm{O}$ group of analogous ketones (Table S6). In addition, the ketone cannot be accommodated in the small cavity formed by the dense coverage of bulky SPOs. Consequently, the ligand imposes severe changes in the conformation and binding geometries of the reactant. This behavior is similar to other catalytic systems based on ligand-modified nanoparticles, for which the ligands limit the accessibility to the active sites and modify the properties of the ligand-metal interface. ${ }^{14,53}$ The results are in line with the control of selectivity by high surface 
coverage on $\mathrm{Pd}$ and $\mathrm{Pt}$ in the hydrogenation of $\alpha, \beta$-unsaturated aldehydes reported in ref 54 .

The hydrogenation of ketones catalyzed by the cluster $\mathrm{Au}_{25}(\mathrm{SR})_{18}$ described in ref 26 presents some crucial differences. The outermost surface structure of $\mathrm{Au}_{25}(\mathrm{SR})_{18}$ is very open, and the heterolytic $\mathrm{H}_{2}$ dissociation occurs because the $\mathrm{C}=\mathrm{O}$ group of the ketone is further stabilized by the protic solvent (ethanol). The hydrogenation then proceeds sequentially, as we have found for the autocatalytic acrolein hydrogenation (see Supporting Information, Section 1). However, for the AuNP-SPO catalyst, the solvent was found to affect the adsorption and desorption of all reactants and products significantly. The presence of an important dipolar interaction in both the adsorption and TS states also explains the preference for apolar solvent. ${ }^{35,36}$ Indeed, the computed solvation energies in THF are the lowest (Table S2), indicating that the adsorption would be more favored. Moreover, the AuNP-SPO catalyst is too crowded due to the presence of the bulky ligands, and consequently, the solvent molecules cannot be accommodated in the small cavity formed by the dense coverage of SPOs. Therefore, the ligand-nanoparticle structure determines the catalytic behavior, and the structure-activity/ selectivity relationships need to be addressed accordingly.

Once the reaction mechanism in the AuNP-SPO is established, the performance for different SPO ligands (L) and reactants $(R)$ can be rationalized. We have taken the experimental results reported in ref 35 with the conditions: 60 ${ }^{\circ} \mathrm{C}, 40 \mathrm{bar}_{2}$, and THF $(5 \mathrm{~mL})$ as solvent. The conversion after $18 \mathrm{~h}$ is taken as indicative of the reaction rate. Out of the 25 experiments performed, the rates of 18 experiments have been correlated to two independent parameters representing the ligand--reactant pair and the catalyst (Figure 5). The experiments for the hydrogenation of $p$-nitrobenzaldehyde were discarded, since the conversion was quantitative and no rate could be extracted. In addition, two points (R1-L5 and R2-L2) were found to be outliers in our description and were

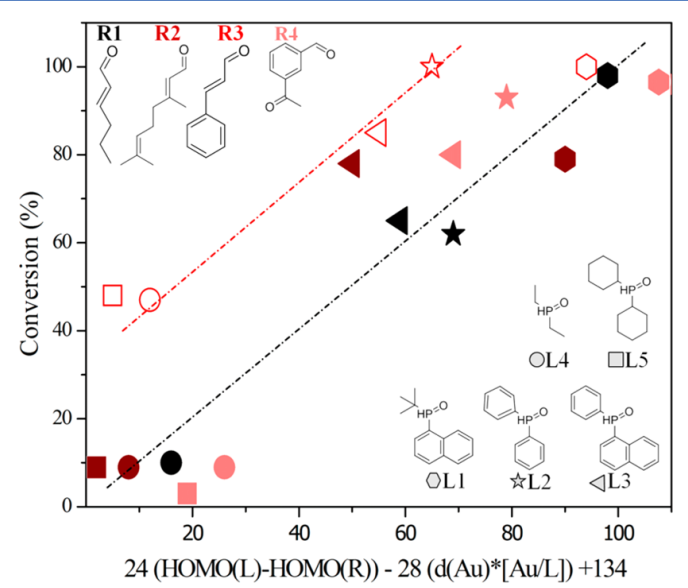

Figure 5. Experimental conversion taken from ref 35 as a function of a two-variable descriptor: the computed differential basicity $\mathrm{HOMO}(\mathrm{L})$ $\mathrm{HOMO}(\mathrm{R})$ (electronic) and the empty sites on the Au nanoparticle surface obtained from the diameter of $\mathrm{AuNP}$ and the $[\mathrm{Au} / \mathrm{L}]$ ratio (geometric) from the experimental determination. The regression coefficient, $r$, is 0.94 . Shapes stand for ligands (L), and colors stand for reactants $(\mathrm{R})$. The red line corresponds to the dependence for R3, which needs an extra term in the fitting equation that includes the lateral chain interaction (dispersion). eliminated from the reaction pool. As we have seen in Figure 5 , the key point for the activity corresponds to the balance between the basicity of the $\mathrm{P}=\mathrm{O}$ bond in $\mathrm{L}$ and that of substrate $\mathrm{R}$. This difference drives the transfer hydrogenation. If $\mathrm{L}$ is very basic, the adsorption of $\mathrm{H}_{2}$ in the form of the ion pair is favored, but excessive stabilization would hamper $\mathrm{H}$-transfer to the $\mathrm{C}=\mathrm{O}$ bond. The simplest descriptor for the basicity contribution is represented by the $\mathrm{HOMO}(\mathrm{L})-\mathrm{HOMO}(\mathrm{R})$ difference. The AuNPs described in ref 35 differ in diameter and $\mathrm{Au}: \mathrm{L}$ ratio. The term representing the catalyst is more difficult to address but relates to the surface to volume $S / V$ exposed in the nanoparticles (Supporting Information, Section 4.2) and the ligand coverage of this surface. When these two terms are multiplied, they constitute a measure of the fraction of nonactive $\mathrm{Au}$ atoms. The multifactorial linear-scaling relationship for the reactivity with electronic and geometric contributions is shown in Figure 5. Technical details are presented in the Supporting Information, Section 4.2, Tables S7 and S8.

Figure 5 shows that the electronic (L-R) and geometric (AuL) terms present a similar contribution. The larger the $\mathrm{HOMO}(\mathrm{L})-\mathrm{HOMO}(\mathrm{R})$ term (Supporting Information, Table S8), the higher the driving force for the transfer hydrogenation is. In addition, the blocked $\mathrm{Au}$ atoms have a detrimental contribution to the activity, so small diameters and low [Au:L] ratios are preferred. The rule found can explain the reactivity not only for relatively simple molecules but also for other more complex ones. This is the case of cinnamaldehyde (R3), which contains conjugated $\mathrm{C}=\mathrm{O}$ and $\mathrm{C}=\mathrm{C}$ bonds and an isolated aromatic ring. In the fitting, only the electronic effect of the L- $\mathrm{R}$ pair and the size-coverage of the nanoparticle are taken into account. R3 possesses an extended $\pi$-system that can interact through van der Waals interactions with the ligands. ${ }^{55,56}$ These contributions are not included in the fitting equation and would result in larger interaction energies with the nanoparticles and thus in longer residence times that would be an extra contribution to activity. Therefore, the deviation in the rate of the empty points corresponding to this substrate can be attributed to the fact that the interaction of R3 is larger than those of the other substrates due to van der Waals contributions of the side chain, which increase the residence time of the reactant and thus its conversion.

\section{CONCLUSION}

In summary, we have shown that SPOs acting as ligands for AuNPs provide an effective Frustrated Lewis Pair that allows the heterolytic activation of $\mathrm{H}_{2}$, which can then be added via a concerted mechanism to unsaturated aldehydes generating valuable unsaturated alcohols. The electronic and geometric terms that control the reaction have been identified and can explain the hydrogenation of four compounds with five different SPO-stabilized AuNPs, showing its rationalization via collective descriptors. The results obtained in this work may provide a wide perspective to design new hybrid catalysts by tuning the ligand.

\section{ASSOCIATED CONTENT}

S Supporting Information

Calculated data for the $\mathrm{H}_{2}$ dissociation and autocatalytic pathway of acrolein and acetone on $\mathrm{Au}_{55}$ nanoparticles; 
adsorption energies, as well as the solvation contribution; reaction mechanism of formation of propanal, prop-2-en1-ol, and 2-propanol on AuNP-SPO and bader charge analysis of aldehydes and ketones; collective descriptors used to explain the activity for a family of SPO-stabilized AuNPs and a set of unsaturated aldehydes. Finally the structural models are in doi.org/10.19061/iochem-bd-125. (PDF)

\section{AUTHOR INFORMATION}

\section{Corresponding Author}

*E-mail: nlopez@iciq.es.

\section{ORCID $\odot$}

Neyvis Almora-Barrios: 0000-0001-5269-2705

Piet W. N. M. van Leeuwen: 0000-0002-2165-7090

Núria López: 0000-0001-9150-5941

\section{Notes}

The authors declare no competing financial interest.

\section{ACKNOWLEDGMENTS}

The authors acknowledge the MINECO project (CTQ201568770-R) and grant FPDI-2013-16194 for financial support. P.v.L. thanks the Université Fédérale Toulouse Midi-Pyrénées for an IDEX Chaire dAttractivité.

\section{REFERENCES}

(1) Liu, P.; Qin, R.; Fu, G.; Zheng, N. J. Am. Chem. Soc. 2017, 139, $2122-2131$.

(2) Witham, C. A.; Huang, W.; Tsung, C.-K.; Kuhn, J. N.; Somorjai, G. A.; Toste, F. D. Nat. Chem. 2010, 2, 36-41.

(3) Boles, M. A.; Ling, D.; Hyeon, T.; Talapin, D. V. Nat. Mater. 2016, 15, 141-153.

(4) Kaushik, A.; Kumar, R.; Arya, S. K.; Nair, M.; Malhotra, B. D.; Bhansali, S. Chem. Rev. 2015, 115, 4571-4606.

(5) Oosterom, G. E.; Reek, J. N. H.; Kamer, P. C. J.; van Leeuwen, P. W. N. M. Angew. Chem., Int. Ed. 2001, 40, 1828-1849.

(6) Jin, R.; Zeng, C.; Zhou, M.; Chen, Y. Chem. Rev. 2016, 116, 10346-10413.

(7) Wang, Y.; Wan, X.-K.; Ren, L.; Su, H.; Li, G.; Malola, S.; Lin, S.; Tang, Z.; Häkkinen, H.; Teo, B. K.; Wang, Q.-M.; Zheng, N. J. Am. Chem. Soc. 2016, 138, 3278-3281.

(8) Cao, Z.; Kim, D.; Hong, D.; Yu, Y.; Xu, J.; Lin, S.; Wen, X.; Nichols, E. M.; Jeong, K.; Reimer, J. A.; Yang, P.; Chang, C. J. J. Am. Chem. Soc. 2016, 138, 8120-8125.

(9) Pei, Y.; Shao, N.; Gao, Y.; Zeng, X. C. ACS Nano 2010, 4, 20092020.

(10) Walter, M.; Akola, J.; Lopez-Acevedo, O.; Jadzinsky, P. D.; Calero, G.; Ackerson, C. J.; Whetten, R. L.; Gronbeck, H.; Hakkinen, H. Proc. Natl. Acad. Sci. U. S. A. 2008, 105, 9157-9162.

(11) Gross, E.; Somorjai, G. A. Top. Catal. 2014, 57, 812-821.

(12) Vilé, G.; Albani, D.; Almora-Barrios, N.; López, N.; PérezRamírez, J. ChemCatChem 2016, 8, 21-33.

(13) Wu, Z.; Hu, G.; Jiang, D.; Mullins, D. R.; Zhang, Q.-F.; Allard, L. F.; Wang, L.-S.; Overbury, S. H. Nano Lett. 2016, 16, 6560-6567.

(14) Marshall, S. T.; O’Brien, M.; Oetter, B.; Corpuz, A.; Richards, R. M.; Schwartz, D. K.; Medlin, J. W. Nat. Mater. 2010, 9, 853-858.

(15) Chen, G.; Xu, C.; Huang, X.; Ye, J.; Gu, L.; Li, G.; Tang, Z.; Wu, B.; Yang, H.; Zhao, Z.; Zhou, Z.; Fu, G.; Zheng, N. Nat. Mater. 2016, $15,564-569$.

(16) Gross, E.; Liu, J. H.; Alayoglu, S.; Marcus, M. A.; Fakra, S. C.; Toste, F. D.; Somorjai, G. A. J. Am. Chem. Soc. 2013, 135, 3881-3886.

(17) Biacchi, A. J.; Schaak, R. E. ACS Nano 2015, 9, 1707-1720.

(18) Tsunoyama, H.; Ichikuni, N.; Sakurai, H.; Tsukuda, T. J. Am. Chem. Soc. 2009, 131, 7086-7093.
(19) Fedorov, A.; Liu, H.-J.; Lo, H.-K.; Copéret, C. J. Am. Chem. Soc. 2016, 138, 16502-16507.

(20) Wu, Z.; Jiang, D.-e.; Mann, A. K. P.; Mullins, D. R.; Qiao, Z.-A.; Allard, L. F.; Zeng, C.; Jin, R.; Overbury, S. H. J. Am. Chem. Soc. 2014, $136,6111-6122$.

(21) Almora-Barrios, N.; Vilé, G.; Garcia-Ratés, M.; Pérez-Ramírez, J.; López, N. ChemCatChem 2017, 9, 604-609.

(22) Albani, D.; Li, Q.; Vile, G.; Mitchell, S.; Almora-Barrios, N.; Witte, P. T.; Lopez, N.; Perez-Ramirez, J. Green Chem. 2017, DOI: $10.1039 / \mathrm{C} 6 \mathrm{GC} 02586 \mathrm{~B}$.

(23) Hakkinen, H. Nat. Chem. 2012, 4, 443-455.

(24) Lu, G.; Zhang, P.; Sun, D.; Wang, L.; Zhou, K.; Wang, Z.-X.; Guo, G.-C. Chem. Sci. 2014, 5, 1082-1090.

(25) Wu, B.; Huang, H.; Yang, J.; Zheng, N.; Fu, G. Angew. Chem. 2012, 124, 3496-3499.

(26) Ouyang, R.; Jiang, D. ACS Catal. 2015, 5, 6624-6629.

(27) Fahlbusch, K.-G.; Hammerschmidt, F.-J.; Panten, J.; Pickenhagen, W.; Schatkowski, D.; Bauer, K.; Garbe, D.; Surburg, H. In Ullmann's Encyclopedia of Industrial Chemistry; Wiley-VCH Verlag GmbH \& Co. KGaA: 2012; Vol. 15, p 73-198.

(28) Ponec, V. Appl. Catal., A 1997, 149, 27-48.

(29) Marinelli, T. B. L. W.; Nabuurs, S.; Ponec, V. J. Catal. 1995, 151, 431-438.

(30) Ide, M. S.; Hao, B.; Neurock, M.; Davis, R. J. ACS Catal. 2012, 2, 671-683.

(31) Echavarren, A. M.; Hashmi, A. S. K.; Toste, F. D. Adv. Synth. Catal. 2016, 358, 1347-1347.

(32) Mohr, C.; Hofmeister, H.; Radnik, J.; Claus, P. J. Am. Chem. Soc. 2003, 125, 1905-1911.

(33) Mohr, C.; Hofmeister, H.; Claus, P. J. Catal. 2003, 213, 86-94.

(34) Zhu, Y.; Qian, H.; Drake, B. A.; Jin, R. Angew. Chem., Int. Ed. 2010, 49, 1295-1298.

(35) Cano, I.; Huertos, M. A.; Chapman, A. M.; Buntkowsky, G.; Gutmann, T.; Groszewicz, P. B.; van Leeuwen, P. W. N. M. J. Am. Chem. Soc. 2015, 137, 7718-7727.

(36) Cano, I.; Chapman, A. M.; Urakawa, A.; van Leeuwen, P. W. N. M. J. Am. Chem. Soc. 2014, 136, 2520-2528.

(37) Fiorio, J. L.; Lopez, N.; Rossi, L. M. ACS Catal. 2017, 7, 29732980.

(38) Kresse, G.; Furthmuller, J. Phys. Rev. B: Condens. Matter Mater. Phys. 1996, 54, 11169-1186.

(39) Kresse, G.; Furthmuller, J. Comput. Mater. Sci. 1996, 6, 15-50.

(40) Blochl, P. E. Phys. Rev. B: Condens. Matter Mater. Phys. 1994, 50, 17953-17979.

(41) Perdew, J. P.; Burke, K.; Ernzerhof, M. Phys. Rev. Lett. 1996, 77, $3865-3868$.

(42) Grimme, S. J. Comput. Chem. 2006, 27, 1787-1799.

(43) Bucko, T.; Hafner, J.; Lebegue, S.; Angyan, J. G. J. Phys. Chem. A 2010, 114, 11814-11824.

(44) Almora-Barrios, N.; Carchini, G.; Blonski, P.; Lopez, N. J. Chem. Theory Comput. 2014, 10, 5002-5009.

(45) Garcia-Ratés, M.; López, N. J. Chem. Theory Comput. 2016, 12, $1331-1341$.

(46) Henkelman, G.; Uberuaga, B. P.; Jónsson, H. J. Chem. Phys. 2000, 113, 9901-9904.

(47) Hammer, B.; Norskov, J. K. Nature 1995, 376, 238-240.

(48) Neu, R. C.; Ouyang, E. Y.; Geier, S. J.; Zhao, X.; Ramos, A.; Stephan, D. W. Dalton Trans. 2010, 39, 4285-4294.

(49) Black, K.; Liu, P.; Xu, L.; Doubleday, C.; Houk, K. N. Proc. Natl. Acad. Sci. U. S. A. 2012, 109, 12860-12865.

(50) Wang, D.; Astruc, D. Chem. Rev. 2015, 115, 6621-6686.

(51) Stephan, D. W.; Erker, G. Angew. Chem., Int. Ed. 2015, 54, 6400-6441.

(52) Castro, P. M.; Gulyas, H.; Benet-Buchholz, J.; Bo, C.; Freixa, Z.; van Leeuwen, P. W. N. M. Catal. Sci. Technol. 2011, 1, 401-407.

(53) Albani, D.; Vile, G.; Mitchell, S.; Witte, P. T.; Almora-Barrios, N.; Verel, R.; Lopez, N.; Pérez-Ramírez, J. Catal. Sci. Technol. 2016, 6, $1621-1631$. 
(54) Tuokko, S.; Pihko, P. M.; Honkala, K. Angew. Chem., Int. Ed. 2016, 55, 1670-1674.

(55) Salorinne, K.; Malola, S.; Wong, O. A.; Rithner, C. D.; Chen, X.; Ackerson, C. J.; Häkkinen, H. Nat. Commun. 2016, 7, 10401-104018.

(56) Karakalos, S.; Xu, Y.; Cheenicode Kabeer, F.; Chen, W.; Rodríguez-Reyes, J. C. F.; Tkatchenko, A.; Kaxiras, E.; Madix, R. J.; Friend, C. M. J. Am. Chem. Soc. 2016, 138, 15243-15250. 